\title{
Cardiovascular Implications and Therapeutic Considerations in COVID-19 Infection
}

\author{
Gregory L. Judson · Benjamin W. Kelemen • Joyce N. Njoroge • \\ Vaikom S. Mahadevan
}

Received: May 6, 2020 / Published online: June 13, 2020

(C) The Author(s) 2020

\section{ABSTRACT}

The ongoing severe acute respiratory syndrome coronavirus 2 (SARS-CoV-2) pandemic has profoundly impacted all fields of medicine. Infection with SARS-CoV-2 and the resulting coronavirus of 2019 (COVID-19) syndrome has multiorgan effects. The pandemic has united researchers from bench to bedside in attempts to understand the pathophysiology of the disease and define optimal treatment strategies. Cardiovascular disease is highly prevalent and a leading cause of death across gender, race, and ethnic groups. As the pandemic spreads, there is increasing concern about the cardiovascular effects of the viral infection and the interaction of infection with existing cardiovascular disease. Additionally, there are concerns about the cardiac effects of the numerous treatment agents under study. It will be essential for cardiologists to understand the interplay between underlying cardiac comorbidities, acute cardiovascular effects of COVID-19

Gregory L. Judson and Benjamin W. Kelemen are co-first authors.

Digital features To view digital features for this article go to https://doi.org/10.6084/m9.figshare.12424835.

G. L. Judson · B. W. Kelemen · J. N. Njoroge .

V. S. Mahadevan ( $\square)$

Division of Cardiology, Department of Medicine,

University of California, San Francisco, CA, USA

e-mail: vaikom.mahadevan@ucsf.edu disease, and adverse effects of new treatments. Here we describe emerging evidence of the epidemiology of SARS-CoV-2 infection and underlying cardiovascular disease, the evidence for direct myocardial injury in SARS-CoV-2 infection, the specific presentations of cardiovascular involvement by SARS-CoV-2, and the cardiac effects of emerging treatments.

Keywords: Cardiovascular implications; Coronavirus; COVID-19; SARS

\section{Key Summary Points}

The SARS-CoV2 virus, which causes COVID-19 infection, has unique cardiovascular manifestations that should be recognized by treating cardiologists.

Specific demographic groups, those with certain cardiovascular comorbidities, and those with evidence of myocardial involvement are especially susceptible to aggressive COVID-19 infection.

COVID-19 infection can lead to myocarditis, decompensated heart failure, myocardial infarction, thrombosis, and arrythmia.

Specific experimental therapies for COVID-19 infection have potential cardiovascular side effects. 


\section{INTRODUCTION}

Coronavirus disease of 2019 (COVID-19) is caused by the severe acute respiratory syndrome coronavirus 2 (SARS-CoV2) and was first reported in Wuhan, China, in December of 2019 [1]. Initial presentations from Wuhan were consistent with viral pneumonia and subsequent deep sequencing confirmed a novel RNA-based virus of the Coronaviridae family. As of June 1, 2020, there are 6.2 million confirmed worldwide cases of COVID-19 with over 375,000 deaths [2]. COVID19 has become a worldwide pandemic and has mobilized healthcare workers in all disciplines.

Since the initial presentation of COVID-19, much has been learned about the pathophysiology and specific cardiovascular manifestations of the disease. Early in the pandemic, there was evidence that those with preexisting cardiovascular conditions were over-represented in cases of severe infection [3]. Since that time, it has become clear that certain racial and ethnic groups are disproportionately affected by COVID-19 [4]. Additionally, COVID-19 appears to have several unique cardiovascular manifestations that cardiologists must understand, including worsening of heart failure, myocarditis, a proclivity for thrombosis, and arrythmia. Finally, the speed at which clinical trials for COVID-19 are being conducted, using both repurposed and new therapies, means that cardiologists must be aware of potential cardiovascular side effects for agents that are not commonly used in cardiovascular practice.

This article is based on previously conducted studies and does not contain any studies with human participants or animals performed by any of the authors.

\section{PATHOPHYSIOLOGY}

SARS-CoV-2 is a novel RNA coronavirus that has emerged as the causative infection responsible for the current COVID-19 pandemic. Other viruses from the coronavirus family include the MERS-CoV virus, responsible for the Middle East Respiratory Syndrome (MERS) outbreak, and the SARS-CoV virus, responsible for the Severe
Acute Respiratory Syndrome (SARS) outbreak [5-8]. Initial infection with SARS-CoV-2 is a process that is still being understood but is known to involve viral $\mathrm{S}$ proteins and host angiotensin-converting enzyme 2 (ACE2) receptor and the transmembrane protease, serine 2 (TMPRSS). SARS-CoV-2 expresses numerous spike (S) proteins on the surface of the viral envelope, which facilitates viral entry into the host cell. TMPRSS, a serine protease expressed on the host cell, primes the viral $\mathrm{S}$ proteins to enable interaction with the host ACE2 receptor [9]. The primed $S$ protein then binds the $S 1$ subunit of the host ACE2 receptor allowing for viral entry into the cell [10]. The role of the ACE2 receptor in human physiology remains under investigation but it is believed to provide counter regulation to the renin-angiotensin system [11, 12]. The ACE2 receptor is commonly found in the lungs in type 2 alveolar cells but is also expressed in vascular endothelium, gut epithelium, and in the proximal tubule in the kidneys [13-15]. The location of the ACE2 receptor is implicated in a multitude of disease presentations associated with SARS-CoV-2 infection. After binding the ACE2 receptor, the virus is internalized, and the viral RNA is released. Immediately, the RNA-dependent RNA polymerase is translated, which allows for viral replication and spread of the infection. The role of the ACE2 receptor expression and blockade within both SARS-CoV-2 infection and disease severity remains controversial, with both protective and deleterious effects hypothesized.

\section{CLINICAL SPECTRUM AND SEVERITY OF DISEASE}

The United States has surpassed other countries worldwide in case numbers with over 1.8 million cases as of June 1, 2020 [16]. The epicenter has spread from China to many European countries and now the USA, with significant clusters around the country. The number of COVID-19-related deaths worldwide has now climbed past 375,000 . Due to the heterogeneity of testing strategies and case ascertainment, mortality rates remain controversial, with estimates ranging from 0.7 to $10.8 \%$. 
COVID-19 has a broad spectrum of severity and phenotypic presentation. The most typical presentation involves consequences of direct respiratory infection ranging from cough and dyspnea to hypoxia to acute respiratory distress syndrome (ARDS). The initial cohort study of COVID-19 patients included data from 552 hospitals in China with 1099 patients with COVID-19 disease [17]. The study reported that the most common symptoms at presentation were cough $(67.8 \%)$, fatigue $(38.1 \%)$, and temperature $\geq 37.5{ }^{\circ} \mathrm{C}(43.8 \%)$. In the largest published cases series of sequential COVID-19 cases from the United States in New York City, of the 5700 patients admitted to 12 different hospitals, $30 \%$ of patients presented with an initial fever and $20 \%$ presented with hypoxia [18]. Tachypnea was present in $17.3 \%$ and tachycardia in $43.1 \%$. Mechanical ventilation was required in $12.2 \%$ of patients and early mortality was seen in $24.5 \%$, with $3.2 \%$ of patients surviving to discharge and $72.2 \%$ remaining in the hospital. Thus, SARS-CoV-2 infection most commonly causes respiratory illness with a wide range of severity and outcomes that is relatively consistent in presentation (cough, dyspnea, fever, and hypoxia) across the globe.

\section{PREVALENCE AND SIGNIFICANCE OF COMORBID ILLNESS}

The preexisting burden of comorbid chronic disease is well recognized to contribute to the severity of SARS-CoV-2 infection and there are concerns that underlying comorbid illnesses play a role in the diverse spectrum of phenotypic presentation. The initial study of 41 patients in Wuhan, China, demonstrated a predominance of male patients $(73 \%)$ with pre-existing comorbidities including diabetes (20\%), hypertension (15\%), and cardiovascular disease (15\%) [1]. The median age of patients in this group was 49 years old. Only $7 \%$ of these initial patients had a history of tobacco use. However, since these initial studies, a number of prospective and retrospective studies out of China have demonstrated higher rates of underlying comorbid conditions. Common underlying comorbidities include hypertension (30-32\%), diabetes (10-28\%), and cardiovascular and coronary artery diseases (11-15\%) [19-21]. Smoking history or obstructive lung disease diagnoses were low, when documented (2-10\%). In these studies, these comorbidities were associated with worse severity of illness and mortality. A review of 44,672 confirmed COVID-19 cases from Wuhan, China, demonstrated increased mortality in patients with cardiovascular disease $(10.5 \%)$, diabetes (7.3\%), and hypertension (6\%), which was significantly higher than the overall case-fatality rate of $2.3 \%$ [22].

In the United States, there are similarities and notable differences from the European and Chinese experience. Among 1482 patients admitted with COVID-19, 54.4\% were men and $74.5 \%$ were over the age of 50 years, with the majority (17.2\%) being over 85 years old [23]. Comorbidities included hypertension (49.7\%), obesity (48.3\%), diabetes mellitus (28.3\%), chronic lung disease (34.6\%), cardiovascular disease; including coronary disease and heart failure $(27.8 \%)$, and, less frequently, renal disease (13.1\%) and immunocompromised conditions $(9.6 \%)$. These initial cases series have shown a similar relationship between underlying cardiac comorbidities with a higher prevalence of hypertension, diabetes, coronary artery disease, and obesity in patients requiring mechanical ventilation [24].

A concerning trend is the alarming rate at which black and Hispanic/Latino Americans are being infected and dying from COVID-19 [25]. There were early data from cities and states across the country indicating higher mortality from COVID19 in black and Hispanic/Latino populations. These included Milwaukee, WI, experiencing a 73\% mortality rate in black patients who make up $26 \%$ of the population; Chicago, IL ( $67 \%$ of the mortality with $32 \%$ of the population); and the states of Louisiana (70\% of the mortality with $32 \%$ of the population) and Michigan (41\% of the mortality with $14 \%$ of the population). In the COVID-NET catchment population of the USA, a higher percentage of black patients were infected (33\%) compared to the percentage of overall population being black (18\%) [23]. This trend has been repeated across the country and has brought into stark reality the devastating 
impact COVID-19 has had on communities of color [26]. While it is well known that black and Hispanic/Latino patients have a higher incidence of diabetes and hypertension, this alone does not explain the increased infected and mortality rates. Studies during prior epidemics have continued to demonstrate similar healthcare disparities on smaller scales likely related to multiple factors including access to care, racial and ethnical stigmas among medical professionals, crowded living conditions, income instability, and continued rates of exposure and protection [27-30]. It is crucial to acknowledge the institutionalized barriers to health as a first step to incite change and narrow the outcome gap and improve healthcare for marginalized individuals.

\section{ACUTE CARDIAC INJURY}

De novo cardiac injury has also been described in patients presenting with COVID-19 disease. Initial studies provide insight into the prevalence and incidence of acute cardiac injury patients presenting with COVID-19. Early studies reported a prevalence of acute cardiac injury of $12 \%$ in the entire cohort as defined by either high sensitivity troponin (Hs Tn) or the $\mathrm{MB}$ fraction of creatinine kinase $(\mathrm{CK}-\mathrm{MB})>99$ th percentile or new echocardiographic or electrocardiographic abnormalities with greater elevations in cardiac biomarkers among patients requiring ICU care $[1,20]$. A metaanalysis further clarified the prevalence of acute cardiac injury among Chinese patients presenting with COVID-19 disease reporting a similar prevalence of acute cardiac injury defined as CK-MB or Hs Tn exceeding the 99th percentile [31]. Case cohort studies included data in patients for whom the outcome and illness course helped further elucidate the role of cardiac injury in COVID-19 disease. Zhou et al. showed that the initial Hs Tn was not dramatically elevated at illness onset, but that in non-survivors there was a rapid rise starting after day 10 that was not seen in survivors [3]. Ruan et al. reported the cause of death in the non-survivors with the majority (53\%) due to respiratory failure but a clinically significant number related to combined respiratory/cardiac failure (33\%) and cardiac failure (7\%) [32]. Based on these studies, the authors hypothesize that myocardial injury occurs frequently in patients with severe COVID disease and that myocardial dysfunction is involved in the pathophysiology of severe disease. As the pandemic progressed and patient outcomes were defined, investigators sought to evaluate the association of myocardial injury with mortality. In a multivariable Cox regression, acute cardiac injury at any point during hospital stay was associated with an increased risk of mortality (HR 4.26, 95\% confidence interval 1.92-9.49). Guo et al. examined the association of cardiac comorbidities and acute cardiac injury as defined by Hs Tn above the 99th percentile with mortality in a retrospective cohort of 187 patients [19]. In this cohort, $28 \%$ of patients had acute cardiac injury. The proportion of non-survivors was increased in the groups with underlying cardiac comorbidities (hypertension, coronary artery disease, and cardiomyopathy) or myocardial injury and highest in groups with both. The authors did not assess measures of association beyond descriptive statistics. Thus, myocardial injury occurs not infrequently with COVID-19 disease and that the presence of myocardial injury portends both more severe disease and higher mortality.

The mechanism of this acute cardiac injury remains elusive. Data from Zhou et al. and Guo et al. have shown that the rise in troponin typically occurs late in the disease process, typically occurring 10-14 days after the onset of symptoms and coincides with progressive respiratory decline and multiorgan failure $[3,19]$. This would suggest that myocardial injury may be a marker for more severe infection and not causally associated. However, there are few reports of systematic cardiac testing of patients with COVID-19 disease, and cardiac injury limited our ability to understand causal associations. A number of mechanisms have been proposed including direct myocardial injury and myocarditis, systemic hyperinflammatory response leading to cytokine storm and myocardial injury, microvascular thromboses, acute plaque rupture physiology, stress cardiomyopathy, and extreme oxygen 
supply-demand mismatch due to critical illness $[33,34]$. The relative mystery surrounding the pathophysiology of acute cardiac injury has resulted in conflicting recommendations regarding the use of troponin to screen and evaluate cardiac dysfunction in patients with COVID-19 disease. A communication by the American College of Cardiology (ACC) recommended against routine cardiac biomarker testing in patients presenting with COVID-19 disease [35]. Subsequent review papers have advocated for systematic use of high-sensitivity troponin as a biomarker of severe illness with proven prognostic value in COVID-19 disease $[34,36]$. However, this risk prediction strategy has not yet been evaluated prospectively.

\section{SPECIFIC CARDIOVASCULAR DISEASE ENTITIES}

\section{Myocarditis and Decompensated Heart Failure}

SARS-CoV2 has been implicated in cases of myocarditis and acute decompensated heart failure. Initial reports of myocarditis from China described cases of cardiogenic shock and reduced left ventricular ejection fraction among COVID-19 patients [37, 38]. These patients had extremely elevated levels of cardiac biomarkers (namely troponin, CK-MB, and BNP) and required inotropy or extracorporeal membrane oxygenation (ECMO) to maintain adequate cardiac output. Based on the clinical presentation and on these elevations in biomarkers, these cases were deemed "fulminant myocarditis" and were treated with a combination of steroids, IVIG, antivirals, antibiotics, anti-inflammatory agents, renal replacement, and mechanical ventilation.

During other outbreaks of similar coronaviruses in the last 20 years, namely SARS-CoV and MERS, there was evidence to support direct myocardial involvement. Among patients who died from SARS-CoV in Toronto, Canada, viral RNA was detected in $35 \%$ of samples and the presence of viral RNA was associated with increased levels of interstitial fibrosis and macrophage activity within the myocardium, thus potentially leading to a more rapid clinical course compared to patients without viral RNA in the myocardium [39]. However, hemodynamically significant myocarditis appears to have been a relatively rare complication of SARS, with one case series noting only one instance of potential myocarditis requiring inotropy among 121 cases [40]. Myocarditis also appears to have been a potential complication during the MERS outbreak, with MRI findings consistent with myocarditis reported [41].

There is now additional evidence that SARSCoV2 has a similar effect on the myocardium as SARS-CoV and MERS. Myocardial involvement has been confirmed in SARS-CoV-2-positive patients via MRI and endomyocardial biopsy [42-44]. Cardiac biopsy findings in COVID-19 patients have shown inflammatory infiltration of the myocardium with T-lymphocyte and macrophages, interstitial edema, and in some cases, evidence of cytoplasmic vacuoles indicating direct viral involvement of myocardial cells $[43,44]$. In a post-mortem case series of 68 patients from China, 7\% of COVID-19 patients died of circulatory failure with some degree of myocardial involvement, as marked by elevations in troponin [32]. However, it is unclear if these cases can truly be classified as myocarditis given the lack of ejection fraction assessment via TTE, MRI, or biopsy. From a different case series in Seattle, WA, troponin elevation was seen in 15\% of patients, but none of the patients who underwent TTE had evidence of a reduced ejection fraction [45]. There is currently no standardized approach to treatment of COVID-19 cardiomyopathy. In cases of more severe "fulminant" myocarditis resulting in cardiogenic shock, treatments with immunomodulating drugs, namely steroids and IVIG, but also more specific agents like tocilizumab to inhibit IL-6, are being used. Clinical trial data is as of yet lacking on the efficacy of such therapies in COVID-19-related myocarditis and are being extrapolated from other causes of fulminant myocarditis, namely giant cell subtype.

Decompensation of pre-existing heart failure appears to be a more common cardiovascular manifestation of SARS-CoV-2 infection than clinically significant myocarditis. Prior to the COVID-19 pandemic, influenza-like respiratory 
infections significantly increased the risk of hospitalization for decompensated heart failure, and in high influenza activity months, may contribute to $19 \%$ of heart failure hospitalizations across the United States [46]. The relationship between respiratory infection and decompensated heart failure appears to also be true for COVID-19-like seasonal influenza. In two retrospective case series from China of 113 and 191 patients, heart failure was observed in $49 \%$ and $52 \%$ of deaths, respectively [3, 47]. There appears to be a broad spectrum of disease severity, ranging from stable to fulminant heart failure requiring inotropes, and potentially mechanical circulatory support for refractory shock and or hypoxia. The use of ECMO in COVID-19 cases is being studied in a prospective manner as part of the Extracorporeal Life Support Organization (ELSO) Registry. As of June 1, 2020, ECMO has been used in 1135 COVID-19-confirmed cases worldwide, with $52 \%$ discharged alive, and the vast majority of patients receiving veno-venous ECMO for respiratory support [48].

There is interest in the role of ACEI/ARB in both the overall risk of COVID-19 and the severity of lung disease with studies suggesting both the possibility of deleterious and beneficial effects [49, 50]. Major guideline committees have continued to advocate for the use of ACE/ ARB medications in hemodynamically stable heart failure patients, hypertension, and those with ischemic heart disease $[51,52]$.

\section{Acute Coronary Syndromes and Thrombosis}

COVID-19 has been hypothesized to increase the risk of acute coronary syndromes (ACS) and systemic thrombosis. This premise is based on prior experience with viral infections such as influenza, which predisposes patients to developing ACS, and may increase the risk of myocardial infarction (MI) by at least sixfold in the week following infection [53]. This increase in MI incidence is also seen following infection with other respiratory infections such as respiratory syncytial virus, and for non-viral respiratory illnesses such as bacterial pneumonia.
Many MIs due to COVID-19 disease are likely related to supply-demand mismatch from hypoxia resulting in myocardial injury and troponin release. However, MI from acute atherothrombotic events were first reported in Wuhan, China, soon after the onset of the pandemic. As such, Chinese hospitals soon developed treatment algorithms aimed at providing urgent reperfusion to COVID-19-suspected patients while maintaining the safety of catheterization lab staff. In the setting of ST-elevation MI (STEMI) and suspected SARS-CoV-2 infection, thrombolytics were often the first choice for acute reperfusion therapy in China [54]. Following this early experience in China, ACC/SCAI released a joint recommendation outlining care for COVID-19-suspected patients [55]. This document highlights the need for adequate personal protective equipment for catheterization lab staff, the need to differentiate true ACS from supply-demand mismatch, consideration of deferring invasive angiography in low-risk non-ST elevation myocardial infarction (NSTEMI) patients until hospital resources improve, and the potential use of thrombolytics for ST segment elevation myocardial infarction (STEMI) cases where the risks of exposing staff to SARS-CoV2 outweigh the benefits of a primary percutaneous coronary intervention (PCI)-based approach. However, the authors still expect primary PCI to remain the standard of care for patients with STEMI and possible COVID-19 and thrombolytics reserved for nonPCI-capable hospitals [56].

Further adding to the complexity of treating these patients, ST-segment elevations are seen in COVID-19 patients who are then found to have non-obstructive coronary disease. In a case series of 18 patients in New York, NY, who developed ST-segment elevations, nine patients underwent invasive angiography. Of these nine patients, three had no obstructive coronary artery disease and 5/6 with obstructive disease underwent PCI (1 after receiving thrombolytics) [57]. These cases of ST-segment elevation with no obstructive coronary disease on angiography may be related to peri-myocarditis, although the pathophysiology remains under investigation. Importantly, the mortality among patients without no obstructive coronary lesion was 
higher (90\%) than among those with obstructive coronary lesions (50\%), although the absolute numbers were limited. A similar incidence of obstructive to non-obstructive coronary lesions was reported in a population of Italian patients with STEMI [58]. The high prevalence of STEMI mimics in this population further emphasizes the need for angiography (either invasive or non-invasive) as opposed to empiric fibrinolytic therapy given the potential for harm when administering fibrinolytics for non-ACS presentations.

While COVID-19 may potentially increase the risk of ACS, activations for STEMI in the United States have decreased significantly during the pandemic. Among nine high-volume centers in the US, there was a $38 \%$ reduction in STEMI activations compared to the 14-month period before the pandemic [59]. This finding is similar to the $40 \%$ reduction in STEMI activations seen in Spain [60]. It is unclear what is responsible for the significant reduction in STEMI activations, but it may be related to patients' fear of exposure to SARS-CoV2 when presenting to the hospital. In Hong Kong, China, patients who presented with STEMI during the height of the outbreak presented to the hospital significantly longer after onset of symptoms compared to a year prior (318 vs. $83 \mathrm{~min}$ ) [61]. It is currently unknown how many people worldwide may not be seeking medical care for possible ACS due to fear of COVID-19. It is possible that due to delays in seeking appropriate medical care, patients may eventually present to the hospital with heart failure, cardiogenic shock, or mechanical complications from ACS. Studies must be performed to assess the impact COVID-19 could have on cardiovascular mortality through such indirect mechanisms.

SARS-CoV2 infection is theorized to predispose to a hypercoagulable state through inflammation, immune dysregulation, and activation of cytokines. This process has been implicated in ACS, but also in cases of thrombosis outside the coronary arteries. Among 184 ICU patients in the Netherlands, 31\% were diagnosed with pulmonary embolism, deep-vein thrombosis, ischemic stroke, myocardial infarction, or systemic embolism-all while receiving standard prophylactic doses of anticoagulation as recommended by the WHO [62]. Remarkably, none of the patients in this study developed disseminated intravascular coagulopathy (DIC), a known risk factor for the development of arterial and venous thromboembolism in critically ill patients. Ddimer levels above $1500 \mathrm{ng} / \mathrm{ml}$ had a sensitivity of $85 \%$ and specificity of $89 \%$ for detecting venous thromboembolism in a cohort from China [63]. Some centers have advocated for the use of treatment dose anticoagulation for select patients with COVID-19 and elevated D-dimer levels, however this practice has yet to be well validated.

\section{Arrhythmia}

Among 187 patients with confirmed SARS-CoV2 in Wuhan, China, arrhythmia occurred in $5.9 \%$ of all patients admitted [19]. Elevated troponin $\mathrm{T}$ was a statistically significant prognostic marker with $82 \%$ having either ventricular tachycardia or fibrillation. It is unclear whether elevated troponin preceded or succeeded the arrhythmic events. Furthermore, among 138 patients admitted to a single hospital in Wuhan, China, arrhythmia (type not specified) was reported in $17 \%$ with the majority $(44 \%)$ occurring in critically ill patients in the intensive care unit [20]. Among patients who suffered a cardiac arrest, the predominant rhythm was asystole/pulseless electrical activity (94\%), followed by shockable ventricular tachycardia/fibrillation (6\%) [64]. Similar rates in the New York City population were reported by Goyal et al. Arrhythmia was seen in $7.4 \%$ of the entire cohort, with higher rates in the patients receiving ICU care $(18.5 \%)$ as compared to non-ICU care (1.8\%) [24]. Arrhythmias may be induced by the presence of acidosis and metabolic disturbances, as seen in critical illness with multiorgan dysfunction or catecholaminergic pressor infusion for hypotension and shock. Finally, QT-prolonging agents given to some COVID-19 patients may increase the susceptibility to arrhythmia as discussed below $[65,66]$. Unfortunately, with the limited data available, no trends have been apparent as of yet $[67,68]$. 


\section{Cardiovascular Considerations with COVID-19 Therapies}

There is suspicion that the aggressive nature of the coronavirus pneumonia is related to an exaggerated immune response mediated by interferon and interleukins, as has been seen in prior coronavirus infections $[69,70]$. Targets for COVID-19 therapies are therefore not only focused on the intrinsic viral make up (including proteins such as ACE- 2 cell surface receptor, 3-chymotrypsin-like protease, Spike, RNA-dependent RNA polymerase, and papain-like protease) but also the human immune system [71].

Table 1 Overview of select clinical trials and potential cardiotoxicities [72-85]

\begin{tabular}{|c|c|c|c|}
\hline General class & Drug & Cardiotoxicities & Clinical trials \\
\hline \multirow{3}{*}{$\begin{array}{l}\text { Repurposed } \\
\text { agents } \\
\text { targeting viral } \\
\text { entry and } \\
\text { replication }\end{array}$} & $\begin{array}{l}\text { Hydroxychloroquine sulfate/ } \\
\text { chloroquine } \\
\text { phosphate } \pm \text { azithromycin }\end{array}$ & $\begin{array}{l}\text { Dilated cardiomyopathy, QT } \\
\text { prolongation }\end{array}$ & $\begin{array}{l}\text { NCT04342221, NCT04307693, } \\
\text { NCT04315896, NCT04329923, } \\
\text { NCT04345692 }\end{array}$ \\
\hline & Lopinavir/ritonavir & $\begin{array}{l}\text { QT prolongation, rhabdomyolysis } \\
\text { with statins }\end{array}$ & $\begin{array}{l}\text { NCT04252885, NCT04307693, } \\
\text { NCT04307693, NCT04255017 }\end{array}$ \\
\hline & Remdesivir & ?hypotension & $\begin{array}{l}\text { NCT04292899, NCT04292730, } \\
\text { NCT04323761, NCT04302766, } \\
\text { NCT0 } 4280705\end{array}$ \\
\hline \multirow{4}{*}{$\begin{array}{l}\text { Repurposed } \\
\text { agents } \\
\text { targeting the } \\
\text { immune } \\
\text { system }\end{array}$} & Corticosteroids & $\begin{array}{l}\text { Fluid retention, hypertension, } \\
\text { electrolyte abnormalities, } \\
\text { arrhythmia }\end{array}$ & $\begin{array}{l}\text { NCT04343729, NCT04329650, } \\
\text { NCT04327401, NCT04344288, } \\
\text { NCT04331054, NCT04348305, } \\
\text { NCT04355247 }\end{array}$ \\
\hline & Tocilizumab & Hypertension, hypercholesterolemia & $\begin{array}{l}\text { NCT04315480, NCT04320615, } \\
\text { NCT04317092, NCT04332913, } \\
\text { NCT04306705, NCT04310228, } \\
\text { NCT04346355, NCT04332094, } \\
\text { NCT04331795 }\end{array}$ \\
\hline & Fingolimod & $\begin{array}{l}\text { Hypertension, conduction disease, } \\
\text { QT prolongation. } \\
\text { Contraindicated in prior MI or } \\
\text { known CAD, stroke, conduction } \\
\text { disease, prolonged QT, } \\
\text { decompensated heart failure }\end{array}$ & NCT04280588 \\
\hline & Convalescent plasma & None reported & $\begin{array}{l}\text { NCT04343755, NCT04346446, } \\
\text { NCT04342182, NCT04347681, } \\
\text { NCT04345523, NCT04344535, } \\
\text { NCT04340050, NCT04357106, } \\
\text { NCT04327349, NCT04292340, } \\
\text { NCT04261426, NCT04264858, } \\
\text { NCT0 } 4261426\end{array}$ \\
\hline
\end{tabular}


There are currently over 350 active clinical trials searching for treatment options for COVID-19 both in novel therapies as well as repurposed existing therapies, which has the benefit of having a known safety profile. The following table summarizes a selection of these drugs, their mechanisms, known and proposed cardiotoxicities, and ongoing clinical trials (Table 1).

\section{CONCLUSIONS}

The ongoing COVID-19 pandemic poses an enormous threat globally. Given the high prevalence of existing cardiovascular disease worldwide, it is not surprising that cardiovascular comorbidities significantly impact disease severity. The unique properties of the SARSCoV-2 infection and pathophysiology further raise concern for de novo cardiac injury with COVID-19. The cardiovascular presentations of COVID-19 are still being elucidated, but appear to at least include decompensated heart failure, myocarditis, ACS, arrhythmia, and thrombosis. The effect of the COVID-19 pandemic on cardiovascular systems of care and whether patients are delaying necessary treatment will be of great importance to understand as the pandemic progresses in the months and years to come. Lastly, emerging therapeutic approaches have expected and unexpected cardiac effects that must be monitored as treatment algorithms expand. Cardiologists will play a vital role in the care of COVID-19 patients worldwide and in the ongoing research into the pathophysiology and population-based effects of the SARS-CoV2 virus.

\section{ACKNOWLEDGEMENTS}

Funding. No funding or sponsorship was received for this study or publication of this article.

Authorship. All named authors meet the International Committee of Medical Journal Editors (ICMJE) criteria for authorship for this article, take responsibility for the integrity of the work as a whole, and have given their approval for this version to be published.

Disclosures. Gregory L. Judson, Benjamin W. Kelemen, Joyce N. Njoroge, and Vaikom S. Mahadevan have nothing to disclose in relation to this article.

Compliance With Ethics Guidelines. This article is based on previously conducted studies and does not contain any studies with human participants or animals performed by any of the authors.

Data Availability. Data sharing is not applicable to this article as no datasets were generated or analyzed during the current study.

Open Access. This article is licensed under a Creative Commons Attribution-NonCommercial 4.0 International License, which permits any non-commercial use, sharing, adaptation, distribution and reproduction in any medium or format, as long as you give appropriate credit to the original author(s) and the source, provide a link to the Creative Commons licence, and indicate if changes were made. The images or other third party material in this article are included in the article's Creative Commons licence, unless indicated otherwise in a credit line to the material. If material is not included in the article's Creative Commons licence and your intended use is not permitted by statutory regulation or exceeds the permitted use, you will need to obtain permission directly from the copyright holder. To view a copy of this licence, visit http://creativecommons.org/licenses/by$\mathrm{nc} / 4.0 /$.

\section{REFERENCES}

1. Huang C, Wang Y, Li X, et al. Clinical features of patients infected with 2019 novel coronavirus in Wuhan, China. Lancet. 2020;395(10223):497-506. https://doi.org/10.1016/S0140-6736(20)30183-5.

2. COVID-19 Map. Johns Hopkins Coronavirus Resource Center. https://coronavirus.jhu.edu/map. html. Accessed 1 Jun 2020 
3. Zhou F, Yu T, Du R, et al. Clinical course and risk factors for mortality of adult inpatients with COVID-19 in Wuhan, China: a retrospective cohort study. Lancet. 2020;395(10229):1054-62. https:// doi.org/10.1016/S0140-6736(20)30566-3.

4. CDC. COVID-19 in Racial and Ethnic Minority Groups. Centers for disease control and prevention. Published Feb 11, 2020. https://www.cdc.gov/ coronavirus/2019-ncov/need-extra-precautions/ racial-ethnic-minorities.html. Accessed 1 Jun 2020

5. Peiris JSM, Lai ST, Poon LLM, et al. Coronavirus as a possible cause of severe acute respiratory syndrome. Lancet. 2003;361(9366):1319-25. https://doi.org/ 10.1016/s0140-6736(03)13077-2.

6. Ksiazek TG, Erdman D, Goldsmith CS, et al. A novel coronavirus associated with severe acute respiratory syndrome. N Engl J Med. 2003;348(20):1953-66. https://doi.org/10.1056/NEJMoa030781.

7. Drosten C, Günther S, Preiser W, et al. Identification of a novel coronavirus in patients with severe acute respiratory syndrome. $\mathrm{N}$ Engl J Med. 2003;348(20):1967-76. https://doi.org/10.1056/ NEJMoa030747.

8. Zaki AM, van Boheemen S, Bestebroer TM, Osterhaus ADME, Fouchier RAM. Isolation of a novel coronavirus from a man with pneumonia in Saudi Arabia. N Engl J Med. 2012;367(19):1814-20. https://doi.org/10.1056/NEJMoa1211721.

9. Hoffmann M, Kleine-Weber H, Schroeder S, et al. SARS-CoV-2 cell entry depends on ACE2 and TMPRSS2 and is blocked by a clinically proven protease inhibitor. Cell. 2020;181(2):271-280.e8. https://doi.org/10.1016/j.cell.2020.02.052.

10. Li W, Moore MJ, Vasilieva N, et al. Angiotensinconverting enzyme 2 is a functional receptor for the SARS coronavirus. Nature. 2003;426(6965):450-4. https://doi.org/10.1038/nature02145.

11. Imai Y, Kuba K, Rao S, et al. Angiotensin-converting enzyme 2 protects from severe acute lung failure. Nature. 2005;436(7047):112-6. https://doi.org/10. $1038 /$ nature03712.

12. Kuba K, Imai $Y$, Rao S, et al. A crucial role of angiotensin converting enzyme 2 (ACE2) in SARS coronavirus-induced lung injury. Nat Med. 2005;11(8): 875-9. https://doi.org/10.1038/nm1267.

13. Hamming I, Timens W, Bulthuis MLC, Lely AT, Navis GJ, van Goor H. Tissue distribution of ACE2 protein, the functional receptor for SARS coronavirus. A first step in understanding SARS pathogenesis. J Pathol. 2004;203(2):631-7. https://doi. org/10.1002/path.1570.
14. Crackower MA, Sarao R, Oudit GY, et al. Angiotensin-converting enzyme 2 is an essential regulator of heart function. Nature. 2002;417(6891):822-8. https://doi.org/10.1038/nature00786.

15. Chen L, Li X, Chen M, Feng Y, Xiong C. The ACE2 expression in human heart indicates new potential mechanism of heart injury among patients infected with SARS-CoV-2. Cardiovasc Res. 2020. https:// doi.org/10.1093/cvr/cvaa078.

16. COVID-19 situation reports. https://www.who.int/ emergencies/diseases/novel-coronavirus-2019/situa tion-reports. Accessed 21 Apr 2020

17. Guan W-J, Ni Z-Y, Hu Y, et al. Clinical characteristics of coronavirus disease 2019 in China. N Engl J Med. 2020;382(18):1708-20. https://doi.org/10. 1056/NEJMoa2002032.

18. Richardson S, Hirsch JS, Narasimhan M, et al. Presenting characteristics, comorbidities, and outcomes among 5700 patients hospitalized with COVID-19 in the New York City area. JAMA. 2020. https://doi.org/10.1001/jama.2020.6775.

19. Guo T, Fan Y, Chen M, et al. Cardiovascular implications of fatal outcomes of patients with coronavirus disease 2019 (COVID-19). JAMA Cardiol. 2020. https://doi.org/10.1001/jamacardio. 2020.1017 .

20. Wang D, Hu B, Hu C, et al. Clinical characteristics of 138 hospitalized patients with 2019 novel coronavirus-infected pneumonia in Wuhan China. JAMA. 2020. https://doi.org/10.1001/jama.2020. 1585.

21. Shi S, Qin M, Shen B, et al. Association of cardiac injury with mortality in hospitalized patients with COVID-19 in Wuhan China. JAMA Cardiol. 2020. https://doi.org/10.1001/jamacardio.2020.0950.

22. Wu Z, McGoogan JM. Characteristics of and important lessons from the coronavirus disease 2019 (COVID-19) outbreak in China: summary of a report of 72,314 cases from the Chinese Center for Disease Control and Prevention. JAMA. 2020. https://doi.org/10.1001/jama.2020.2648.

23. Garg S, Kim L, Whitaker M, et al. Hospitalization rates and characteristics of patients hospitalized with laboratory-confirmed coronavirus disease 2019COVID-NET, 14 states, March 1-30, 2020. MMWR Morb Mortal Wkly Rep. 2020;69(15):458-64. https:// doi.org/10.15585/mmwr.mm6915e3.

24. Goyal P, Choi JJ, Pinheiro LC, et al. Clinical characteristics of Covid-19 in New York City. N Engl J Med. 2020. https://doi.org/10.1056/NEJMc2010419. 
25. Thebault $\mathrm{R}$, Tran $\mathrm{AB}$, Williams $\mathrm{V}$. The coronavirus is infecting and killing black Americans at an alarmingly high rate. Washington Post. https://www. washingtonpost.com/nation/2020/04/07/coronavir us-is-infecting-killing-black-americans-an-alarming ly-high-rate-post-analysis-shows/. Published 7 Apr 2020. Accessed 21 Apr 2020

26. Haynes N, Cooper LA, Albert MA, Association of Black Cardiologists. At the heart of the matter: unmasking and addressing COVID-19's toll on diverse populations. Circulation. 2020. https://doi. org/10.1161/CIRCULATIONAHA.120.048126.

27. Phelan JC, Link BG. Is racism a fundamental cause of inequalities in health? Ann Rev Sociol. 2015;41(1):311-30. https://doi.org/10.1146/ annurev-soc-073014-112305.

28. Quinn SC, Kumar S, Freimuth VS, Musa D, Casteneda-Angarita N, Kidwell K. Racial disparities in exposure, susceptibility, and access to health care in the US H1N1 influenza pandemic. Am J Public Health. 2011;101(2):285-93. https://doi.org/10. 2105/AJPH.2009.188029.

29. Hadler JL, Yousey-Hindes K, Pérez A, et al. Influenza-related hospitalizations and poverty levels-United States, 2010-2012. MMWR Morb Mortal Wkly Rep. 2016;65(5):101-5. https://doi. org/10.15585/mmwr.mm6505a1.

30. Obermeyer Z, Powers B, Vogeli C, Mullainathan S. Dissecting racial bias in an algorithm used to manage the health of populations. Science. 2019;366(6464):447-53. https://doi.org/10.1126/ science.aax 2342 .

31. Lippi G, Lavie CJ, Sanchis-Gomar F. Cardiac troponin I in patients with coronavirus disease 2019 (COVID-19): evidence from a meta-analysis. Prog Cardiovasc Dis. 2020. https://doi.org/10.1016/j. pcad.2020.03.001.

32. Ruan Q, Yang K, Wang W, Jiang L, Song J. Clinical predictors of mortality due to COVID-19 based on an analysis of data of 150 patients from Wuhan, China. Intensive Care Med. 2020. https://doi.org/ 10.1007/s00134-020-05991-x.

33. Atri D, Siddiqi HK, Lang J, Nauffal V, Morrow DA, Bohula EA. COVID-19 for the cardiologist: a current review of the virology, clinical epidemiology, cardiac and other clinical manifestations and potential therapeutic strategies. JACC Basic Transl Sci. 2020. https://doi.org/10.1016/j.jacbts.2020.04.002.

34. Hendren NS, Drazner MH, Bozkurt B, Cooper LT. Description and proposed management of the acute COVID-19 cardiovascular syndrome. Circulation. 2020. https://doi.org/10.1161/CIRCULATIONAHA. 120.047349 .
35. Troponin and BNP Use in COVID-19. American College of Cardiology.https://www.acc.org/latestin-cardiology/articles/2020/03/18/15/25/troponinand-bnp-use-in-covid19. Accessed 21 Apr 2020

36. Chapman AR, Bularga A, Mills NL. High-sensitivity cardiac troponin can be an ally in the fight against COVID-19. Circulation. 2020. https://doi.org/10. 1161/CIRCULATIONAHA.120.047008.

37. Hu H, Ma F, Wei X, Fang Y. Coronavirus fulminant myocarditis treated with glucocorticoid and human immunoglobulin. Eur Heart J. 2020. https://doi. org/10.1093/eurheartj/ehaa190.

38. Zeng J-H, Liu Y-X, Yuan J, et al. First case of COVID19 complicated with fulminant myocarditis: a case report and insights. Infection. 2020. https://doi. org/10.1007/s15010-020-01424-5.

39. Oudit GY, Kassiri Z, Jiang C, et al. SARS-coronavirus modulation of myocardial ACE2 expression and inflammation in patients with SARS. Eur J Clin Invest. 2009;39(7):618-25. https://doi.org/10.1111/ j.1365-2362.2009.02153.x.

40. Yu C, Wong RS, Wu EB, et al. Cardiovascular complications of severe acute respiratory syndrome. Postgrad Med J. 2006;82(964):140-4. https://doi. org/10.1136/pgmj.2005.037515.

41. Alhogbani T. Acute myocarditis associated with novel Middle East Respiratory Syndrome coronavirus. Ann Saudi Med. 2016;36(1):78-80. https:// doi.org/10.5144/0256-4947.2016.78.

42. Inciardi RM, Lupi L, Zaccone $\mathrm{G}$, et al. Cardiac involvement in a patient with coronavirus disease 2019 (COVID-19). JAMA Cardiol. 2020. https://doi. org/10.1001/jamacardio.2020.1096.

43. Sala S, Peretto G, Gramegna M, et al. Acute myocarditis presenting as a reverse Tako-Tsubo syndrome in a patient with SARS-CoV-2 respiratory infection. Eur Heart J. 2020. https://doi.org/10. 1093/eurheartj/ehaa286.

44. Tavazzi G, Pellegrini C, Maurelli M, et al. Myocardial localization of coronavirus in COVID-19 cardiogenic shock. Eur J Heart Fail. 2020. https://doi. org/10.1002/ejhf.1828.

45. Bhatraju PK, Ghassemieh BJ, Nichols $M$, et al. Covid-19 in critically ill patients in the Seattle region-case series. N Engl J Med. 2020. https://doi. org/10.1056/NEJMoa2004500.

46. Kytömaa S, Hegde S, Claggett B, et al. Association of influenza-like illness activity with hospitalizations for heart failure: the Atherosclerosis Risk in Communities Study. JAMA Cardiol. 2019;4(4):363-9. https://doi.org/10.1001/jamacardio.2019.0549. 
47. Chen $\mathrm{T}, \mathrm{Wu} \mathrm{D}$, Chen $\mathrm{H}$, et al. Clinical characteristics of 113 deceased patients with coronavirus disease 2019 retrospective study. BMJ. 2020;2020:368. https://doi.org/10.1136/bmj.m1091.

48. Extracorporeal Life Support Organization-ECMO and ECLS $>$ Registry $>$ Full COVID-19 Registry Dashboard. https://www.elso.org/Registry/ FullCOVID19RegistryDashboard.aspx. Accessed 17 Apr 2020

49. Fang L, Karakiulakis G, Roth M. Are patients with hypertension and diabetes mellitus at increased risk for COVID-19 infection? Lancet Respir Med. 2020;8(4):e21. https://doi.org/10.1016/S22132600(20)30116-8.

50. Zhang P, Zhu L, Cai J, et al. Association of inpatient use of angiotensin converting enzyme inhibitors and angiotensin II receptor blockers with mortality among patients with hypertension hospitalized with COVID-19. Circ Res. 2020. https://doi.org/10. 1161/CIRCRESAHA.120.317134.

51. Position Statement of the ESC Council on Hypertension on ACE-Inhibitors and Angiotensin Receptor Blockers. https://www.escardio.org/Councils/ Council-on-Hypertension-(CHT)/News/position-sta tement-of-the-esc-council-on-hypertension-on-aceinhibitors-and-ang, https://www.escardio.org/ Councils/Council-on-Hypertension-(CHT)/News/ position-statement-of-the-esc-council-on-hypertension-on-ace-inhibitors-and-ang. Accessed 17 Apr 2020

52. HFSA/ACC/AHA Statement Addresses Concerns Re: Using RAAS Antagonists in COVID-19. American College of Cardiology. https://www.acc.org/latestin-cardiology/articles/2020/03/17/08/59/hfsa-accaha-statement-addresses-concerns-re-using-raasantagonists-in-covid-19. Accessed 17 Apr 2020

53. Kwong JC, Schwartz KL, Campitelli MA, et al. Acute myocardial infarction after laboratory-confirmed influenza infection. N Engl J Med. 2018;378(4): 345-53. https://doi.org/10.1056/NEJMoa1702090.

54. Jing Z-C, Zhu H-D, Yan X-W, Chai W-Z, Zhang S. Recommendations from the Peking Union Medical College Hospital for the management of acute myocardial infarction during the COVID-19 outbreak. Eur Heart J. 2020. https://doi.org/10.1093/ eurheartj/ehaa258.

55. Welt FGP, Shah PB, Aronow HD, et al. Catheterization Laboratory considerations during the coronavirus (COVID-19) pandemic: from ACC's Interventional Council and SCAI. J Am Coll Cardiol. 2020. https://doi.org/10.1016/j.jacc.2020.03. 021.

56. Mahmud E, Dauerman HL, Welt FG, et al. Management of acute myocardial infarction during the
COVID-19 pandemic. J Am Coll Cardiol. 2020. https://doi.org/10.1016/j.jacc.2020.04.039.

57. Bangalore S, Sharma A, Slotwiner A, et al. ST-segment elevation in patients with Covid-19-a case series. N Engl J Med. 2020. https://doi.org/10.1056/ NEJMc2009020.

58. Stefanini GG, Montorfano M, Trabattoni D, et al. ST-Elevation myocardial infarction in patients with COVID-19: clinical and angiographic outcomes. Circulation. 2020. https://doi.org/10.1161/ CIRCULATIONAHA.120.047525.

59. Garcia S, Albaghdadi MS, Meraj PM, et al. Reduction in ST-segment elevation cardiac catheterization laboratory activations in the United States during COVID-19 pandemic. J Am Coll Cardiol. 2020. https://doi.org/10.1016/j.jacc.2020.04.011.

60. Rodríguez-Leor O, Alvarez-Álvarez B, Ojeda S, et al. Impacto de la pandemia de COVID-19 sobre la actividad asistencial en cardiología intervencionista en España. REC Interv Cardiol. 2020. https://doi. org/10.24875/RECIC.M20000120.

61. Tam C-CF, Cheung K-S, Lam S, et al. Impact of coronavirus disease 2019 (COVID-19) outbreak on ST-segment-elevation myocardial infarction care in Hong Kong, China. Circ Cardiovasc Qual Outcomes. 2020. https://doi.org/10.1161/ CIRCOUTCOMES.120.006631.

62. Klok FA, Kruip MJHA, van der Meer NJM, et al. Incidence of thrombotic complications in critically ill ICU patients with COVID-19. Thromb Res. 2020. https://doi.org/10.1016/j.thromres.2020.04.013.

63. Tang N, Bai H, Chen X, Gong J, Li D, Sun Z. Anticoagulant treatment is associated with decreased mortality in severe coronavirus disease 2019 patients with coagulopathy. J Thromb Haemost. 2020. https://doi.org/10.1111/jth.14817.

64. Shao F, Xu S, Ma X, et al. In-hospital cardiac arrest outcomes among patients with COVID-19 pneumonia in Wuhan, China. Resuscitation. 2020. https://doi.org/10.1016/j.resuscitation.2020.04.005.

65. Lazzerini PE, Laghi-Pasini F, Bertolozzi I, et al. Systemic inflammation as a novel QT-prolonging risk factor in patients with torsades de pointes. Heart. 2017;103(22):1821-9. heartjnl-2016-311079.

https://doi.org/10.1136/

66. Lazzerini PE, Boutjdir M, Capecchi PL. COVID-19, arrhythmic risk and inflammation: mind the gap! Circulation. 2020. https://doi.org/10.1161/ CIRCULATIONAHA.120.047293.

67. Kochi AN, Tagliari AP, Forleo GB, Fassini GM, Tondo C. Cardiac and arrhythmic complications in 
patients with COVID-19. J Cardiovasc Electrophysiol. 2020. https://doi.org/10.1111/jce.14479.

68. Akhmerov A, Marban E. COVID-19 and the Heart. Circ Res. 2020. https://doi.org/10.1161/ CIRCRESAHA.120.317055.

69. Omrani AS, Saad MM, Baig K, et al. Ribavirin and interferon alfa-2a for severe Middle East Respiratory Syndrome coronavirus infection: a retrospective cohort study. Lancet Infect Dis. 2014;14(11):1090-5. https://doi.org/10.1016/S1473-3099(14)70920-X.

70. Driggin E, Madhavan MV, Bikdeli B, et al. Cardiovascular considerations for patients, health care workers, and health systems during the coronavirus disease 2019 (COVID-19) pandemic. J Am Coll Cardiol. 2020. https://doi.org/10.1016/j.jacc.2020. 03.031 .

71. Sanders JM, Monogue ML, Jodlowski TZ, Cutrell JB. Pharmacologic treatments for coronavirus disease 2019 (COVID-19): a review. JAMA. 2020. https:// doi.org/10.1001/jama.2020.6019.

72. Tang W, Cao Z, Han M, et al. Hydroxychloroquine in patients with COVID-19: an open-label, randomized, controlled trial. medRxiv. 2020. https:// doi.org/10.1101/2020.04.10.20060558.

73. Colson P, Rolain J-M, Lagier J-C, Brouqui P, Raoult D. Chloroquine and hydroxychloroquine as available weapons to fight COVID-19. Int J Antimicrob Agents. 2020. https://doi.org/10.1016/j.ijantimicag. 2020.105932 .

74. Bosseboeuf E, Aubry M, Nhan T, et al. Azithromycin inhibits the replication of zika virus. J Anti Antiretrovir. 2020. https://doi.org/10.4172/19485964.1000173.

75. Page RL, O'Bryant CL, Cheng D, et al. Drugs that may cause or exacerbate heart failure: a scientific statement from the American Heart Association. Circulation. 2016;134(6):e32-69. https://doi.org/ 10.1161/CIR.0000000000000426.

76. Tönnesmann E, Kandolf R, Lewalter T. Chloroquine cardiomyopathy $-\mathrm{a}$ review of the literature.
Immunopharmacol Immunotoxicol. 2013;35(3): 434-42. https://doi.org/10.3109/08923973.2013. 780078 .

77. Cao B, Wang Y, Wen D, et al. A trial of lopinavirritonavir in adults hospitalized with severe Covid19. N Engl J Med. 2020. https://doi.org/10.1056/ NEJMoa2001282.

78. KALETRA ${ }^{\circledR}$ oral film coated tablets, oral solution, lopinavir ritonavir oral film coated tablets, oral solution. Product Insert

79. Siegel D, Hui HC, Doerffler E, et al. Discovery and synthesis of a phosphoramidate prodrug of a pyrrolo[2,1-f][triazin-4-amino] adenine C-nucleoside (GS-5734) for the treatment of Ebola and emerging viruses. J Med Chem. 2017;60(5):1648-61. https:// doi.org/10.1021/acs.jmedchem.6b01594.

80. Mulangu S, Dodd LE, Davey RT, et al. A randomized, controlled trial of Ebola virus disease therapeutics. N Engl J Med. 2019;381(24):2293-303. https://doi.org/10.1056/NEJMoa1910993.

81. Meduri GU, Golden E, Freire AX, et al. Methylprednisolone infusion in early severe ARDS: results of a randomized controlled trial. Chest. 2007;131(4):954-63. https://doi.org/10.1378/chest. 06-2100.

82. Fang X, Mei Q, Yang T, et al. Low-dose corticosteroid therapy does not delay viral clearance in patients with COVID-19. J Infect. 2020. https://doi. org/10.1016/j.jinf.2020.03.039.

83. Yang Z, Liu J, Zhou Y, Zhao X, Zhao Q, Liu J. The effect of corticosteroid treatment on patients with coronavirus infection: a systematic review and meta-analysis. J Infect. 2020. https://doi.org/10. 1016/j.jinf.2020.03.062.

84. Xu X, Han M, Li T, et al.(2020) Effective treatment of severe COVID-19 patients with tocilizumab 12

85. Shen C, Wang Z, Zhao F, et al. Treatment of 5 critically ill patients with COVID-19 with convalescent plasma. JAMA. 2020. https://doi.org/10. 1001/jama.2020.4783. 